DOI: 10.12731/2658-6649-2020-12-2-84-88

УДК 796/799

\title{
ОСОБЕННОСТИ \\ КРОВООБРАЩЕНИЯ В ВЕРХНИХ КОНЕЧНОСТЯХ ПРИ ДОЗИРОВАННОЙ ВЕЛОЭРГОМЕТРИИ
}

Николаева Т.М., Голубева Е.К.

Проведено исследование интенсивности кровотока в сегменте «плечо-предплечье» при дозированной физической нагрузке на велоэогометре. Для изучения особенностей регионального кровообращения использовался метод реовазографии. Выявлено снижение тонуса артериальных сосудов верхних конечностей и увеличение кровенаполнения при мощңности физической нагрузки, составляющей $2 \mathrm{Bm} / \kappa 2$.

Ключевые слова: физическая нагрузка; периферический кровоток; реовазография.

\section{FEATURES \\ OF BLOOD CIRCULATION IN THE UPPER LIMBS WITH DOSED BICYCLE ERGOMETRY}

\author{
Nikolaeva T.M., Golubeva E.K.
}

A study was made of the intensity of blood flow in the segment of the "shoulder-forearm" at a dosed physical load on the bicycle meter. The rheovasography method was used to study the features of regional blood circulation. A decrease in the tone of the arterial vessels of the upper extremities and an increase in blood supply were detected with a physical load of $2 \mathrm{~W} / \mathrm{kg}$.

Keywords: physical activity; peripheral blood flow; rheovasography.

\section{Актуальность}

Воздействие физических нагрузок на организм приводит к изменениям адаптивного характера во всех звеньях системы кровообращения, что определяет функциональную устойчивость организма. Поэтому актуальным является изучение региональной гемодинамики при адаптации сосудистой системы в условиях воздействия мышечных нагрузок. Известно, 
что физическая нагрузка сопровождается перераспределением кровотока в пользу работающих мышц [1]. Большинство исследований посвящено изучению регионального кровообращения в нижних конечностях у профессиональных спортсменов, которые испытывают регулярное воздействие физических нагрузок только в этом сегменте $[2,4]$. Однако, возможные гемодинамические изменения в сосудах, непосредственно не участвующих в кровоснабжении работающих мышц и находящихся на значительном удалении от них, практически не исследованы.

\section{Цель работы}

Выявить особенности кровотока в верхних конечностях при велоэргометрии с различной мощностью нагрузки.

\section{Материалы и методы}

В исследовании приняли участие 10 мужчин-добровольцев, имеющие нормальное физическое развитие и нормальный двигательный режим

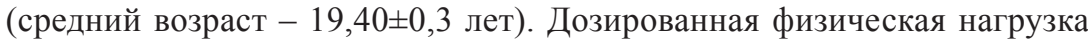
моделировалась с помощью велоэргометра. Мощность нагрузки составляла 1 Вт/кг и 2 Вт/кг массы тела при скорости вращения педалей 50 оборотов в минуту. Для исследования регионального кровотока на участках «плечо», «предплечье» применяли реографический аппаратно-программный комплекс «Рео-Спектр» компании «Нейрософт» (Иваново) [3]. Определяли следующие параметры: базовое сопротивление тела (Zбазов.), максимальная амплитуда артериальной компоненты (Аарт.), реографический индекс (РИ), амплитудно-частотный показатель (АЧП), максимальная скорость быстрого наполнения (Vмакс.), средняя скорость медленного наполнения (Vcp.). Статистическая обработка полученных результатов производилась в электронных таблицах Excel c расчетом среднего арифметического, среднего квадратического отклонения, ошибки среднего. Статистическая значимость различий определялась с помощью t-критерия Стьюдента. Различия считались статистически значимыми при $\mathrm{p} \leq 0,05$.

\section{Результаты исследования}

Анализ параметров артериального и венозного кровотока в верхних конечностях (плечо-предплечье) после физической нагрузки мощностью $1 \mathrm{BT} /$ кг массы тела показал отсутствие статистически значимых изменений по сравнению с контролем. 
Физическая нагрузка 2Вт/кг сопровождается снижением базового сопротивления во всех исследуемых участках (табл. 1). Базовое сопротивление дает наиболее полное представление о пульсовых колебаниях электрического сопротивления. Чем больше кровенаполнение, тем меньше сопротивление исследуемой области. Одновременно происходит снижение РИ в левом плече и в правом предплечье. Реографический индекс зависит от частоты сердечных сокращений, артериального давления, величины ударного объема крови, а также от состояния тонуса сосудистой стенки и, как правило, имеет тенденцию к уменьшению при снижении Z базового.

\section{Изменение показателей РВГ верхних конечностей при велоэргометрии (мощность нагрузки - 2 Вт/кг)}

\begin{tabular}{|l|c|c|}
\hline \multicolumn{1}{|c|}{ Показатель } & Контроль & Опыт \\
\hline Zбазов. левое плечо & $168,00 \pm 14,39$ & $148,20 \pm 6,33^{*}(\mathrm{p}=0,03)$ \\
\hline Zбазов. правое плечо & $197,70 \pm 9,25$ & $172,80 \pm 5,5^{*}(\mathrm{p}=0,04)$ \\
\hline Zбазов. левое предплечье & $203,10 \pm 11,81$ & $168,70 \pm 5,43^{*}(\mathrm{p}=0,02)$ \\
\hline Zбазов. правое предплечье & $174,90 \pm 4,97$ & $151,10 \pm 4,28^{*}(\mathrm{p}=0,002)$ \\
\hline РИ левое плечо & $0,23 \pm 0,02$ & $0,11 \pm 0,02^{*}(\mathrm{p}=0,001)$ \\
\hline РИ правое плечо & $0,26 \pm 0,07$ & $0,20 \pm 0,04$ \\
\hline РИ левое предплечье & $0,22 \pm 0,05$ & $0,20 \pm 0,02$ \\
\hline РИ правое предплечье & $0,20 \pm 0,03$ & $0,12 \pm 0,02^{*}(\mathrm{p}=0,04)$ \\
\hline Аарт. левое плечо & $0,02 \pm 0,003$ & $1,10 \pm 0,22^{*}(\mathrm{p}=0,001)$ \\
\hline Аарт. правое плечо & $0,03 \pm 0,04$ & $3,19 \pm 0,39^{*}(\mathrm{p}=0,00002)$ \\
\hline Аарт. левое предплечье & $0,03 \pm 0,05$ & $2,60 \pm 0,16^{*}(\mathrm{p}=0,000001)$ \\
\hline Аарт. правое предплечье & $0,02 \pm 0,002$ & $1,24 \pm 0,18^{*}(\mathrm{p}=0,0001)$ \\
\hline
\end{tabular}

Примечание: * - статистически значимые различия $(\mathrm{p} \leq 0,05)$.

Во всех исследуемых сегментах верхних конечностей наблюдается увеличение амплитуды артериальной компоненты, свидетельствуя об увеличении пульсового кровенаполнения в условиях увеличения силы сокращения сердца. В правом плече отмечается статистически значимое увеличение АЧП до $0,46 \pm 0,04$ при $0,33 \pm 0,05$ в контроле ( $\mathrm{p}=0,004)$. Амплитудно-частотный показатель отражает интенсивность артериального кровотока в исследуемом сегменте в зависимости от ЧСС, которая увеличивается после физической нагрузки.

Контрольный показатель средней скорости медленного наполнения в правом предплечье составляет $0,19 \pm 0,02$, а после физической нагрузки $2 \mathrm{BT} / \kappa г$ Vср. уменьшается до $0,13 \pm 0,01(\mathrm{p}=0,04)$. Это может быть связано 
со снижением тонуса средних и мелких артерий. Наблюдаемое при этом снижение Vмaх. в правом плече до $0,59 \pm 0,05$ при 0,64 $\pm 0,09$ в контроле $(\mathrm{p}=0,04)$, указывает на уменьшение тонуса крупных сосудов.

Таким образом, физическая нагрузка мощностью 1 Вт/кг не вызывает существенных изменений реовазографических показателей в сегменте плечо-предплечье. Повышение мощности нагрузки до 2 Вт/кг приводит к увеличению степени кровенаполнения сосудов обеих верхних конечностей при снижении скорости кровенаполнения справа, указывающем на уменьшение тонуса артериальных сосудов.

\section{Список литературы}

1. Баранова Е.А. Физиологическая адаптация системы внешнего дыхания и регионарного кровотока спортсменов к интенсивным физическим нагрузкам. Томск, 2014. 103 с.

2. Дратцев, Е.Ю., Викулов, Л.Д., Мельников, А.А., Алехин, В.В. Состояние регионального кровообращения у спортсменов высокой квалификации // Вестник спортивной науки, 2008, №3. С. 32-35.

3. Комплекс реографический «Рео-Спектр»: методические указания. Иваново: ООО «Нейрософт», 2010. 152 с.

4. Кудря О.Н., Кирьянова М.А., Капилевич Л.В. Особенности периферической гемодинамики спортсменов при адаптации к нагрузкам различной направленности // Бюллетень сибирской медицины, № 3, 2012. С. 48-52.

\section{References}

1. Baranova E.A. Fiziologicheskaya adaptatsiya sistemy vneshnego dykhaniya $i$ regionarnogo krovotoka sportsmenov $k$ intensivnym fizicheskim nagruzkam [Physiological adaptation of the system of external respiration and regional blood flow of athletes to intense physical exertion]. Tomsk, 2014. $103 \mathrm{p}$.

2. Drattsev, E.Yu., Vikulov, L.D., Mel'nikov, A.A., Alekhin, V.V. Vestnik sportivnoy nauki, 2008, №3, pp. 32-35.

3. Kompleks reograficheskiy «Reo-Spektr»: metodicheskie ukazaniya [Complex reographic "Reo-Spectrum": guidelines]. Ivanovo: OOO «Neyrosoft», 2010. 152 p.

4. Kudrya O.N., Kir'yanova M.A., Kapilevich L.V. Byulleten'sibirskoy meditsiny, № 3, 2012, pp. 48-52.

\section{ДАННЫЕ ОБ АВТОРАХ}

Николаева Татьяна Михайловна, ассистент ФГБОУ ВО ИвГМА Минздрава России 
пр-т Шереметевский, 8, г. Иваново, Ивановская область, 153012, Российская Федерация

Tania020480@yandex.ru

Голубева Елена Константиновна, д. м. н., доцент

ФГБОУ ВО ИвГМА Минздрава России

пр-т Шереметевский, 8, г. Иваново, Ивановская область, 153012,

Российская Федераиия

elkgol@yandex.ru

DATA ABOUT THE AUTHORS

Nikolaeva Tatyana Mikhaylovna, assistant

Ivanovo State Medical Academy

8, Sheremetevsky, Ivanovo, Ivanovo Region, 153012, Russian Federation Tania020480@yandex.ru

Golubeva Elena Konstantinovna, Doctor of Medicine, Associate Professor Ivanovo State Medical Academy

8, Sheremetevsky, Ivanovo, Ivanovo Region, 153012, Russian Federation elkgol@yandex.ru 